\title{
Coinfecção da Hepatite B e Delta na Amazônia: Artigo de atualização
}

\author{
Coinfection Hepatitis B and Delta in the Amazon: Update article
}

\author{
Coinfección Hepatitis B y Delta en la Amazonia: Artículo de actualización
}

Paula Lavigne de Sousa Costa ${ }^{1 *}$, Monique de Almeida Hingel de Andrade ${ }^{1}$, Victor Vieira Silva ${ }^{1}$, Ana Carolina Cunha Costa ${ }^{1}$, Ayumi Miura Fialho da Silva ${ }^{1}$, Poliana da Silva Oliveira ${ }^{1}$, Caroline Lobato Pantoja ${ }^{1}$, Ana Paula Santos Oliveira Brito ${ }^{2}$, Hamilton Cezar Rocha Garcia ${ }^{2}$, Andrey de Almeida Carneiro ${ }^{3}$.

\section{RESUMO}

Objetivo: Discutir os achados na literatura referentes a coinfecção Hepatite B e Delta na Amazônia. Métodos: Os dados foram coletados mediante revisão da literatura com base no PRISMA, a partir dos descritores "Coinfecção", "HBV", "Hepatite B", "Hepatite D" e "Amazônia", publicados no Scielo, Lilacs, MedLine e Pubmed. O estudo foi realizado mediante a análises de artigos originais e de revisão on-line nos idiomas português, espanhol e inglês nos últimos 5 anos. Como critério de exclusão foram estabelecidos artigos repetitivos, além de artigos não pertinentes à busca dos descritores. Resultados: Coletou-se 30 artigos científicos, nos quais 12 estavam dentro dos critérios de exclusão e 18 trabalhos nos de inclusão. Os quais apontam que ambos os vírus são transmitidos, principalmente, por via sexual. Quanto à variabilidade genética, o HBV possui oito genótipos bem característicos. A clínica é variada, havendo a necessidade de o HDV ter a presença do HBV para o curso da doença. O interferon peguilhado é a melhor escolha terapêutica. Além disso, novos medicamentos estão sendo desenvolvidos visando um tratamento mais acessível e eficaz. Conclusão: A literatura brasileira acerca da co-infecção do vírus da hepatite $\mathrm{B}$ e $\mathrm{D}$ carece de estudos de melhor evidência, evidenciando a necessidade de novas pesquisas.

Palavras-chave: Coinfecção, HBV, Hepatite B, Hepatite D, Amazônia.

\section{ABSTRACT}

Objective: To present, describe and discuss the findings of the literature related to hepatitis $B$ and Delta coinfection in the Amazon. Methods: Data were collected by literature review based on PRISMA, using the keywords Coinfection, HBV, Hepatitis B, Hepatitis D and Amazon, published in Scielo, Lilacs, MedLine and Pubmed. How to apply to include selected items and original online review articles in Portuguese, Spanish, and English in the last 5 years. As exclusion criteria, repetitive articles were specified, besides articles not relevant to the search of the descriptors. Results: We collected 30 scientific articles, in which 12 were within the exclusion requirements and 18 papers in the inclusion. Which point out that both viruses are mainly transmitted sexually. As for genetic variability, HBV has eight very characteristic genotypes. The clinic is variable, requiring HDV with presence of HBV for the course of the disease. Pegylated interferon is the best therapeutic choice. In addition, new drugs are being followed by more affordable and effective treatment.

\footnotetext{
${ }^{1}$ Centro Universitário Faculdade Metropolitana da Amazônia (UNIFAMAZ), Belém - PA.

*E-mail: paulalavigne9@hotmail.com

2 Universidade do Estado do Pará (UEPA), Belém - PA

${ }^{3}$ Centro Universitário do Pará (CESUPA), Belém - PA.
} 
Conclusion: The Brazilian literature on hepatitis B and D virus co-infection receives better evidence studies, highlighting the need for further research.

Keywords: Coinfection, HBV, Hepatitis B, Hepatitis D, Amazon.

\section{RESUMEN}

Objetivo: presentar, describir y discutir los hallazgos de la literatura relacionada con la coinfección por hepatitis $B$ y Delta en la Amazonía. Métodos: los datos se recopilaron mediante una revisión de la literatura basada en PRISMA, utilizando las palabras clave Coinfección, VHB, Hepatitis B, Hepatitis D y Amazon, publicados en Scielo, Lilacs, MedLine y Pubmed. Cómo presentar una solicitud para incluir artículos seleccionados y artículos originales de revisión en línea en portugués, español e inglés en los últimos 5 años. Como criterios de exclusión, se especificaron artículos repetitivos, además de artículos no relevantes para la búsqueda de los descriptores. Resultados: Recopilamos 30 artículos científicos, en los cuales 12 estaban dentro de los requisitos de exclusión y 18 artículos en la inclusión. Lo que señala que ambos virus se transmiten principalmente por vía sexual. En cuanto a la variabilidad genética, el VHB tiene ocho genotipos muy característicos. La clínica es variable, requiere HDV con presencia de HBV para el curso de la enfermedad. El interferón pegilado es la mejor opción terapéutica. Además, los nuevos medicamentos están siendo seguidos por un tratamiento más económico y efectivo. Conclusión: La literatura brasileña sobre la coinfección por el virus de la hepatitis $B$ y $D$ recibe mejores estudios de evidencia, destacando la necesidad de más investigación.

Palabras clave: Coinfección, VHB, Hepatitis B, Hepatitis D, Amazon.

\section{INTRODUÇÃO}

O vírus da hepatite B (VHB) foi caracterizado em 1971 e em 1977 foi descoberto um novo antígeno no núcleo das células hepáticas infectadas pelo VHB, sendo este denominado de antígeno Delta (OLIVEIRA MS, et al., 2015; LORENC B, et al., 2017). O Vírus da hepatite D (VHD) é considerado um vírus incompleto, pois requer a presença do antígeno de superfície do VHB (HBsAg) para a montagem de partículas virais infecciosas, já que este fornece moléculas que servem de invólucro e proteção para o VHD (VILLA DI FILIPPO D, et al., 2015; GHADIR MR, et al., 2012).

Atualmente, as infecções por vírus B e D constituem um grave problema de saúde pública mundial. Na América do Sul, predominantemente na Bacia Amazônica, casos de hepatite grave e insuficiência hepática têm sido geralmente associados à infecção VHD e, no Brasil, apresentam indicadores elevados na região Amazônica, concentrando-se na Amazônia Ocidental.

De 1999 a 2017 foram notificados no SINAN, 587.821 casos confirmados de hepatites virais sendo 37,1\% de Hepatite B e $0,7 \%$ de hepatite D. A região Norte acumula $75 \%$ do total de casos de hepatite $D$ no Brasil. Em 2017 foram notificados 159 casos no país sendo 87 (54,7\%) na região Norte onde a maioria dos casos foi no sexo masculino e a forma crônica foi a que apresentou maior percentual na classificação clínica dos casos notificados (VILLA DI FILIPPO D, et al., 2015; MINISTÉRIO DA SAÚDE, 2018). Sua origem de diversidade genética tem relação com uma área isolada geograficamente. Até o momento, 8 genótipos foram identificados e classificados como HDV-1 a HDV-8 (CRISPIM MAE, et al., 2014; BOTELHO-SOUZA LF, et al., 2017).

O HBV é um vírus de DNA (Ácido desoxirribonucleico), pertencente à família Hepadnaviridae e sua partícula viral é envolvida por um envelope lipoproteico que contém suas 3 formas de antígenos: o HBcAg, localizado no núcleo; HBsAg, localizado na superfície; e o HBeAg, antígeno presente durante os processos replicativos do vírus. Enquanto o HDV é membro da família Deltaviridae com genoma RNA (ácido ribonucleico), capaz de infectar também vegetais, que possui também um envelope bilíídico com as 3 formas do HBsAg, dos quais do HDV depende para continuar seu ciclo reprodutivo. A única proteína codificar essencialmente por esse vírus é o HDV-Ag (MINISTÉRIO DA SAÚDE, 2015; ZHANG, 2018). 
Quanto ao seu ciclo replicativo, o HBV infecta células hepáticas, sendo internalizado por endocitose. Após a liberação de seu genoma, este será incorporado à célula e utilizado para produção de novas partículas virais (CHABROLLES, et al, 2018). Já o HDV se liga com células hepáticas por meio de uma proteína de superfície do HBsAg e um receptor de membrana, adentrando o complexo celular, de modo que o HBV é necessário para o contato inicial entre o HDV e o hospedeiro, para então iniciar a formação de novas partículas virais (MINISTÉRIO DA SAÚDE, 2015).

O quadro clínico das hepatites virais agudas é diversificado, variando de forma assintomática à insuficiência hepática aguda grave. Predominam sintomas inespecíficos, iniciados 3 a 7 dias depois da infecção, como fadiga, anorexia e náuseas. Também podem ocorrer sintomas típicos de síndromes hepáticas, como colúria, acolia fecal e icterícia. A forma crônica da hepatite costuma ser assintomática, causando sintomas apenas quando atingem níveis mais avançados, como carcinoma hepatocelular e cirrose hepática (MINISTÉRIO DA SAÚDE, 2015; FARCI P e NIRO GA, 2012).

A coinfecção do HBV e HDV é capaz de levar a infecção crônica com complicações como: poliartrite, glomerulonefrite, polimialgia reumática, crioglobulinemia, especialmente cirrose hepática e carcinoma hepatocelular $(\mathrm{CHC})$ devido a circulação de imunocomplexos de mais de uma classe de imunoglobulinas. A possibilidade de coinfecção deve ser sempre pensada nos pacientes que apresentarem boa resposta ao tratamento anti-HBV com baixa replicação do vírus, mas, mesmo assim, apresentam inflamação ativa e progresso hepático negativo (LORENC B, et al., 2017). Desse modo, este artigo objetiva apresentar, discutir e revisar os achados da literatura referentes a coinfecção Hepatite B e Delta na Amazônia.

\section{MÉTODOS}

Tal revisão foi elaborada de acordo com o método PRISMA (Principais itens para Relatar Revisões sistem[áticas e Meta-análises), anteriormente denominado QUORUM (Qualidade dos Relatos de Metaanálises), o qual é constituído por um check list de 27 itens, os quais buscam padronizar o processo de escrita de revisões sistemáticas, conforme sintetizado pelos autores desse trabalho no (Quadro 1) (GALVÃO TF, et al., 2015).

Os dados foram coletados mediante revisão de literatura utilizando descritores do DECs (Descritores em ciências da Saúde) e MeSH (Medical Subject Headings), como: "Coinfecção", "HBV", "Hepatite B", "Hepatite D", "Amazônia".

Como base de dados foram usadas: Scielo, Lilacs, MedLine, Pubmed. Como critérios de inclusão foram estabelecidos artigos originais e de revisão sistemática, desde que publicados integralmente on-line nos idiomas português, espanhol e inglês no período de 2014 a 2019, utilizando os descritores já citados acima nos idiomas previamente selecionados.

Também foram incluídos artigos fora do período supracitado, desde que possuíssem grande pertinência para elaboração deste trabalho. Como critérios de exclusão desconsiderou-se artigos publicados fora do período estabelecido, artigos que não tratavam diretamente da Hepatite B e Delta. Dissertações, capítulos de livros e manuscritos também foram excluídos, assim como trabalhos que não apresentaram no título, resumo ou texto acerca assunto chave desta revisão.

A seleção dos artigos a partir dos descritores citado foi realizada nas seguintes etapas:

- Exclusão inicial dos artigos com base apenas nos seus títulos e nos critérios de inclusão e exclusão definidos pelos autores no processo metodológico.

- Exclusão secundária dos artigos selecionados na etapa anterior com base nos seus resumos, também comparando aos critérios de inclusão e exclusão elaborados pelos autores.

- Leitura integral dos artigos restantes das etapas anteriores e manutenção apenas daqueles que se adequaram aos critérios de exclusão e inclusão e foram considerados pertinentes para construção desse trabalho. 
Quadro 1 - Simplificação dos principais itens do Check list PRISMA.

\begin{tabular}{|c|c|}
\hline Seção do trabalho & Descrição do item \\
\hline Título & $\begin{array}{l}\text { O título deve deixar claro o tipo de artigo em questão, seja ele } \\
\text { revisão sistemática e/ou metanálise. }\end{array}$ \\
\hline Resumo & $\begin{array}{l}\text { O mesmo deve ser estruturado e possuir todos os tópicos } \\
\text { encontrados dentro do artigo, destacando os principais pontos } \\
\text { dele. }\end{array}$ \\
\hline Introdução & $\begin{array}{l}\text { Discursar acerca do assunto a ser abordado, dados atualizados } \\
\text { dos mesmos e a importância da realização de uma revisão de } \\
\text { literatura sobre o tema. }\end{array}$ \\
\hline Objetivo & $\begin{array}{l}\text { Esclarecer que será feita discussão e análise dos artigos } \\
\text { selecionados pelos autores como pertinentes disponíveis na } \\
\text { literatura médica. }\end{array}$ \\
\hline Metodologia & $\begin{array}{l}\text { - Esclarecer se foi seguido um protocolo de construção de } \\
\text { revisões sistemáticas e oferecer referências para o acesso do } \\
\text { mesmo pelos leitores. } \\
\text { - Definir os descritores de pesquisas utilizados e as plataformas } \\
\text { de pesquisas de dados que foram escolhidas. } \\
\text { - Delimitar as características dos artigos a serem selecionados, } \\
\text { como anos de publicação, revistas, tipos de estudos, idioma. } \\
\text { - Selecionar critérios para exclusão de artigos que possam } \\
\text { interferir negativamente ou que não se adequam à construção } \\
\text { desse artigo. } \\
\text { - Descrever todas as etapas sequenciais realizadas pelos } \\
\text { autores, desde leitura de títulos, resumos e íntegra do estudo e } \\
\text { como foi feita a análise deles por meios dos critérios de inclusão } \\
\text { e exclusão. }\end{array}$ \\
\hline Resultados & $\begin{array}{l}\text { - Apresentar o número total de artigos encontrados e o número } \\
\text { dos incluídos nessa revisão em cada etapa do processo de } \\
\text { seleção. }\end{array}$ \\
\hline Discussão & $\begin{array}{l}\text { - Sumarizar os principais resultados e sua força de evidência, } \\
\text { conforme disponibilidade. } \\
\text { - Tratar da importância dos achados de acordo com grupos } \\
\text { específicos, como profissionais da saúde, usuários do sistema de } \\
\text { saúde e para formulação de novas políticas públicas. } \\
\text { - Discutir limitações e vieses na elaboração da revisão } \\
\text { sistemática }\end{array}$ \\
\hline Conclusão/Considerações finais & $\begin{array}{l}\text { Relatar interpretação geral dos resultados e discussão } \\
\text { supracitados e destacar relevância do estudo em questão. }\end{array}$ \\
\hline Financiamento & $\begin{array}{l}\text { Descrever fontes de financiamento e suporte para construção da } \\
\text { revisão sistemática, se houverem os mesmos. }\end{array}$ \\
\hline
\end{tabular}

Fonte: Costa PLS, et al., 2019.

\section{RESULTADOS E DISCUSSÃO}

Os autores delimitaram o total de 35 artigos de acordo com a metodologia anteriormente citada, dentre estes apenas 26 foram mantidos com base na aplicação dos critérios de exclusão e inclusão. 
Quadro 2 - Artigos utilizados para confecção dessa revisão sistemática.

\begin{tabular}{|c|c|c|c|c|}
\hline Autores & Ano & Revista & Objetivo & $\begin{array}{l}\text { Principais resultados } \\
\end{array}$ \\
\hline $\begin{array}{l}\text { Bogomolov } P \text {, et } \\
\text { al. (2016) }\end{array}$ & 2016 & $\begin{array}{l}\text { Journal of } \\
\text { Hepatology }\end{array}$ & $\begin{array}{l}\text { Reportar os resultados de um estudo piloto em } \\
\text { pacientes com infecção crônica por hepatite D } \\
\text { tratados com myrcludex B, inferferon alfa } \\
\text { peguilhado ou sua combinação. }\end{array}$ & $\begin{array}{l}\text { Myrcludex B foi bem tolerado, sem efeitos } \\
\text { colaterais. Obteve excelentes resultados na } \\
\text { redução sérica do HDV RNA e normalizou as } \\
\text { dosagens de ALT quando comparado à } \\
\text { monoterapia. }\end{array}$ \\
\hline $\begin{array}{l}\text { Botelho-souza } \\
\text { LF, et al. (2017) }\end{array}$ & 2017 & Virology Journal & $\begin{array}{l}\text { Revisar e reunir os principais aspectos clínicos e } \\
\text { virológicos da hepatite delta }\end{array}$ & $\begin{array}{l}\text { Há falta de uma medicação efetiva no tratamento } \\
\text { da hepatite delta. Porém, há relatos de sucesso } \\
\text { terapêutico com diminuição dos níveis de HDV e } \\
\text { HBsAg, além de normalização de ALT, em } \\
\text { pacientes tratados com IFN-peguilhado. }\end{array}$ \\
\hline $\begin{array}{l}\text { Yurdaydin C, et } \\
\text { al. (2019) }\end{array}$ & 2019 & $\begin{array}{l}\text { Journal of } \\
\text { hepatology }\end{array}$ & $\begin{array}{l}\text { Avaliar os dados existentes acerca do tratamento } \\
\text { da infecção por HDV e sugerir metas de tratamento } \\
\text { que possam ser usadas no seguimento de } \\
\text { diferentes ensaios clínicos }\end{array}$ & $\begin{array}{l}\text { Futuros ensaios clínicos devem considerar as } \\
\text { interações virais entre HBV e HDV. Dentre as } \\
\text { substâncias estudadas, o myrcludex B é o que } \\
\text { apresenta melhor resposta e esta é progressiva } \\
\text { de acordo com a duração terapêutica. Enquanto o } \\
\text { Lonafarnib tem respostas virais precoces mais } \\
\text { profundas. }\end{array}$ \\
\hline $\begin{array}{l}\text { Coghill S, et al. } \\
(2018)\end{array}$ & 2018 & $\begin{array}{l}\text { International } \\
\text { Journal of } \\
\text { Infectious } \\
\text { Diseases }\end{array}$ & $\begin{array}{l}\text { Investigar a epidemiologia, características clínicas } \\
\text { e desfechos da infecção pelo vírus da hepatite } \\
\text { delta em Queensland, Austrália. }\end{array}$ & $\begin{array}{l}\text { Em Queensland, os pacientes com HDV sérico } \\
\text { positivo são nascidos no exterior, particularmente } \\
\text { na África. Além disso, infecção por HDV está } \\
\text { associado com redução da viremia pelo HBV e } \\
\text { doença hepática mais avançada. }\end{array}$ \\
\hline $\begin{array}{l}\text { Crispim MA, et al. } \\
(2014)\end{array}$ & 2014 & $\begin{array}{l}\text { BMC Infectious } \\
\text { Diseases }\end{array}$ & $\begin{array}{l}\text { Descrever os genótipos de HBV e HDV circulantes } \\
\text { na região amazônica brasileira. }\end{array}$ & $\begin{array}{l}\text { HBV/A prevaleceu, sendo seguido pelo HBV/D e } \\
\text { F. Sendo que o HBV/A predominou em doadores } \\
\text { de sangue. Apenas o genótipo } 3 \text { do HDV foi } \\
\text { detectado, sendo predominante HBV/F-HDV/3 e } \\
\text { HBV/D-HDV/3. }\end{array}$ \\
\hline $\begin{array}{l}\text { Farci P, Nigo GA. } \\
(2012)\end{array}$ & 2012 & $\begin{array}{l}\text { Seminars in liver } \\
\text { disease }\end{array}$ & Descrever as características clínicas da hepatite D & $\begin{array}{l}\text { O HDV tem alta patogenicidade e a hepatite D } \\
\text { crônica gera grande dificuldade para terapia } \\
\text { antiviral. A falta de uma vacina específica para o } \\
\text { HDV seria o único meio de eliminar o risco de } \\
\text { superinfecção. }\end{array}$ \\
\hline
\end{tabular}

REAS/EJCH | Vol.Sup.n.41 | e1421 | DOI: https://doi.org/10.25248/reas.e1421.2020 Página 5 de 12 


\section{Revista Eletrônica Acervo Saúde / Electronic Journal Collection Health ｜ ISSN 2178-2091}

\begin{tabular}{|c|c|c|c|c|}
\hline $\begin{array}{l}\text { Ghadir M, et al. } \\
(2012)\end{array}$ & 2012 & Hepat Mon & $\begin{array}{l}\text { Determinar a prevalência de hepatite } \mathrm{D} \text { na } \\
\text { população da província de Qom e o fator de risco } \\
\text { potencial para adquirir HDV. }\end{array}$ & $\begin{array}{l}\text { A prevalência de infecção por hepatite D na } \\
\text { Província de Qom é de 0,03\%. Sendo que a } \\
\text { prevalência de hepatite D em pacientes HBsAg } \\
\text { positivos foi de } 2 \% \text {. Não houver significância da } \\
\text { relação de hepatite D com tatuagens, histórico } \\
\text { cirúrgico e dentário. }\end{array}$ \\
\hline $\begin{array}{l}\text { Han Z, et al. } \\
(2011)\end{array}$ & 2011 & Plos One & $\begin{array}{l}\text { Mostrar que o RNA do HDV é apenas } \\
\text { parcialmente inibiado pelo uso do interferon. }\end{array}$ & $\begin{array}{l}\text { A inibição da replicação do HDV é real, porém } \\
\text { pouco eficiente, necessitando de concentrações } \\
\text { maiores de interferon. }\end{array}$ \\
\hline $\begin{array}{l}\text { Koh C, et al. } \\
(2015)\end{array}$ & 2015 & The Lancet & $\begin{array}{l}\text { Determinar os efeitos do inibidor de prenilação } \\
\text { lonafarmib nos níveis de HDV RNA em pacientes } \\
\text { com hepatite D crônica. }\end{array}$ & $\begin{array}{l}\text { Tratamento do HDV crônico com lonafarnib } \\
\text { reduziu significativamente os níveis do vírus } \\
\text { circulante. Sendo que essa redução foi } \\
\text { diretamente relacionada com os níveis séricos da } \\
\text { droga. }\end{array}$ \\
\hline $\begin{array}{l}\text { Lorenc B, et al. } \\
(2017)\end{array}$ & 2017 & $\begin{array}{l}\text { Clinical and } \\
\text { Experimental } \\
\text { Hepatology }\end{array}$ & $\begin{array}{l}\text { Apresentar } 2 \text { casos de infecção por Hepatite B, C e } \\
\text { D }\end{array}$ & $\begin{array}{l}\text { Infecção por HDV deve ser considerada em } \\
\text { pacientes com HBV minireplicação. Aultos níveis } \\
\text { de aminotransferases e progressão da doença } \\
\text { hepática invés de uma boa resposta à terapia } \\
\text { para hepatite B. }\end{array}$ \\
\hline $\begin{array}{l}\text { Makhlouf NA, et } \\
\text { al. (2019) }\end{array}$ & 2019 & $\begin{array}{l}\text { Journal of } \\
\text { Infection and } \\
\text { public health }\end{array}$ & $\begin{array}{l}\text { Estimar a prevalência de Infecção por HDV entre } \\
\text { pacientes com HBsAg positivo no alto egito e } \\
\text { determinar características clínicas, laboratoriais e } \\
\text { virológicas dos pacientes com hepatite D. }\end{array}$ & $\begin{array}{l}43 \% \text { dos pacientes com HBsAg positivo foram } \\
\text { soropotivos para anti-HDV.. }\end{array}$ \\
\hline $\begin{array}{l}\text { Ministério da } \\
\text { Saúde - } \\
\text { Secretaria de } \\
\text { vigilância em } \\
\text { Saúde. (2018) }\end{array}$ & 2018 & $\begin{array}{l}\text { Boletim } \\
\text { epidemiológico } \\
\text { - Hepatites } \\
\text { virais }\end{array}$ & $\begin{array}{l}\text { Prestar informações acerca de dados } \\
\text { epidemiológicos referentes às hepatites em todo } \\
\text { território nacional brasileiro. }\end{array}$ & $\begin{array}{l}\text { A região Norte acumula } 75 \% \text { do total de casos de } \\
\text { hepatite D no Brasil. Em } 2017 \text { foram notificados } \\
159 \text { casos no país sendo } 87 \text { (54,7\%) na região } \\
\text { Norte. }\end{array}$ \\
\hline $\begin{array}{l}\text { Ministério da } \\
\text { saúde - } \\
\text { Secretaria de } \\
\text { vigilância em } \\
\text { saúde. (2015) }\end{array}$ & 2015 & $\begin{array}{l}\text { Manual técnico } \\
\text { para diagnóstico } \\
\text { das hepatites } \\
\text { virais }\end{array}$ & $\begin{array}{l}\text { Ampliar as possibilidades de diagnóstico das } \\
\text { hepatites virais e orientar profissionais da saúde } \\
\text { nos passos necessários à realização do } \\
\text { diagnóstico das hepatites virais. }\end{array}$ & $\begin{array}{l}\text { O quadro clínico das hepatites virais é } \\
\text { diversificado. }\end{array}$ \\
\hline
\end{tabular}

REAS/EJCH | Vol.Sup.n.41 | e1421 | DOI: https://doi.org/10.25248/reas.e1421.2020 Página 6 de 12 


\begin{tabular}{|c|c|c|c|c|}
\hline $\begin{array}{l}\text { Ministerio da } \\
\text { saúde - } \\
\text { Secretaria de } \\
\text { vigilância em } \\
\text { saúde. (2017) }\end{array}$ & 2017 & $\begin{array}{l}\text { Protocolo clínico } \\
\text { e diretrizes } \\
\text { terapêuticas } \\
\text { para Hepatite B } \\
\text { e coinfecções }\end{array}$ & $\begin{array}{l}\text { Promover instrução de profissionais da saúde, } \\
\text { fortalecer a promoção à saúde, vigilância, } \\
\text { prevenção e controle dos agravos. }\end{array}$ & $\begin{array}{l}\text { Uso de marcadores sérico de imunidade (anti- } \\
\text { HBs), verificar a presença do antígeno na } \\
\text { superfície do HBV (HBsAg). }\end{array}$ \\
\hline $\begin{array}{l}\text { Noureddin M. e } \\
\text { Gish R. (2014) }\end{array}$ & 2014 & $\begin{array}{l}\text { Current } \\
\text { gastroenterology } \\
\text { reports }\end{array}$ & $\begin{array}{l}\text { Reunir e discutir os principais achados literários } \\
\text { que envolvem a epidemiologia, o diagnóstico e o } \\
\text { manejo da hepatite D após } 36 \text { anos de sua } \\
\text { descoberta. }\end{array}$ & $\begin{array}{l}\text { Há maiores evidências apontando a transmissão } \\
\text { sexual do vírus. O tratamento atual para o HDV é } \\
\text { baseado no IFN, mas novos estudos apontam } \\
\text { sobre o uso de outros medicamentos. São } \\
\text { necessários mais estudos internacionais e } \\
\text { consciência populacional acerca da infecção por } \\
\text { HDV. }\end{array}$ \\
\hline $\begin{array}{l}\text { Oliveira MS, et al. } \\
(2015)\end{array}$ & 2015 & $\begin{array}{l}\text { Revista de } \\
\text { epidemiologia e } \\
\text { controle de } \\
\text { infecção }\end{array}$ & $\begin{array}{l}\text { Correlacionar aspectos clínicos, bioquímicos e } \\
\text { sorológicos entre pacientes com infecção por VHB } \\
\text { e superinfecção por VHD. }\end{array}$ & $\begin{array}{l}\text { O grupo com infecção associada ao vírus } \mathrm{D} \\
\text { apresentou pior prognóstico do que o grupo com } \\
\text { moninfecção pelo vírus } B \text {. }\end{array}$ \\
\hline Rizzeto M. (2015) & 2015 & $\begin{array}{l}\text { Cold Spring } \\
\text { Harbor } \\
\text { perspectives in } \\
\text { medicine }\end{array}$ & $\begin{array}{l}\text { Discutir os principais pontos epidemiológicos da } \\
\text { hepatite } D \text {. }\end{array}$ & $\begin{array}{l}\text { Hepatite D continua um problema médico comum } \\
\text { em usuários de drogas injetáveis, assim como } \\
\text { imigrantes vindos de áreas endêmicas, os quais } \\
\text { acabam por reintroduzir a infecção no continente } \\
\text { europeu. }\end{array}$ \\
\hline $\begin{array}{l}\text { Shirvani- } \\
\text { Dastgerdi E, et al. } \\
(2016)\end{array}$ & 2016 & $\begin{array}{l}\text { Current opinion } \\
\text { in virology }\end{array}$ & $\begin{array}{l}\text { Dissertar acerca dos mecanismos fisiopatológicos } \\
\text { associados com o desenvolvimento de } \\
\text { hepatocarcinoma por hepatite B, C e D. }\end{array}$ & $\begin{array}{l}\text { O mecaniso que envolve as transformações } \\
\text { malignas que culminam no hepatocarcinoma } \\
\text { permanecem não entedidos, parcialmente devido } \\
\text { à falta de modelos experimentais adequadas para } \\
\text { dissecção in vivo do processo da doença. }\end{array}$ \\
\hline $\begin{array}{l}\text { Siederdissen HCZ } \\
\text { e Cornberg M. } \\
(2016)\end{array}$ & 2016 & $\begin{array}{l}\text { Visceral } \\
\text { medicine }\end{array}$ & $\begin{array}{l}\text { Revisar o conhecimento atual do manejo da } \\
\text { monoinfecção por HDV e da co-infecção por } \\
\text { HBV/HDV com ênfase especial na cirrose. }\end{array}$ & $\begin{array}{l}\text { Tratamento precoce da infecção crônica por } \\
\text { hepatite B e D é importante para prevenir as } \\
\text { complicações da cirrose. }\end{array}$ \\
\hline $\begin{array}{l}\text { Silva ALS, et al. } \\
(2012)\end{array}$ & 2012 & $\begin{array}{l}\text { Revista } \\
\text { Brasileira de } \\
\text { Clínica médica }\end{array}$ & $\begin{array}{l}\text { Revisar os aspectos clínico-epidemiológicos, } \\
\text { diagnósticos, terapêticos e profiláticos das } \\
\text { infecções virais por tais agentes. }\end{array}$ & $\begin{array}{l}\text { Destaque-se a importância da avaliação } \\
\text { diagnóstica, da instituição da terapêutica } \\
\text { adequada e do emprego das medidas preventivas } \\
\text { para tais infecções, elementos que devem ser } \\
\text { solidamente conhecidas pelo clínico. }\end{array}$ \\
\hline
\end{tabular}

REAS/EJCH | Vol.Sup.n.41 | e1421 | DOI: https://doi.org/10.25248/reas.e1421.2020 Página 7 de 12 


\section{Revista Eletrônica Acervo Saúde / Electronic Journal Collection Health ｜ ISSN 2178-2091}

\begin{tabular}{|c|c|c|c|c|}
\hline SBH (2015) & 2015 & $\begin{array}{l}\text { Sociedade } \\
\text { Brasileira de } \\
\text { Hepatologia }\end{array}$ & $\begin{array}{l}\text { Apresentar aos profissionais de saúde as principais } \\
\text { recomendações da } \mathrm{SBH} \text { acerca do diagnóstico e } \\
\text { tratamento da hepatite B e D }\end{array}$ & $\begin{array}{l}\text { Indica-se terapia análogos de nucleotídeos e IFN } \\
\text { para pacientes VHB e HDV-RNA positivos por } 48 \\
\text { semanas. }\end{array}$ \\
\hline Tackle F. (2019) & 2019 & $\begin{array}{l}\text { Deutsche } \\
\text { medizinische } \\
\text { wochenschrift }\end{array}$ & $\begin{array}{l}\text { Descrever o tratamento atual e futura para hepatite } \\
\text { B e D }\end{array}$ & $\begin{array}{l}\text { As terapias atuais atuam primariamente } \\
\text { alcançado a supressão viral e mais raramente } \\
\text { negativando o HBsAg. Novas estratégias e novos } \\
\text { medicamentos têm sido desenvolvidos em } \\
\text { ensaios clínicos, a exemplo do Myrcludez que é } \\
\text { um inibidor potencialmente usado no futuro } \\
\text { próximo. }\end{array}$ \\
\hline Villa, et al. (2015) & 2015 & Virology Journal & $\begin{array}{l}\text { Identificar os casos de HDV e/ou HBV } \\
\text { assintomáticos entre ameríndios do estado do } \\
\text { Amazonas, sudeste da Colômbia, e descrever os } \\
\text { genótipos virais circulantes nessas populações. }\end{array}$ & $\begin{array}{l}\text { Foi encontrado uma alta frequência de casos no } \\
\text { estado do Amazonas e na Colômbia. A circulação } \\
\text { de HDV } 3 \text { e HBV-F1B sugere que a circulação } \\
\text { destes genótipos decorre da interação de ambas } \\
\text { as populações. }\end{array}$ \\
\hline $\begin{array}{l}\text { Wranke A, et al. } \\
(2018)\end{array}$ & 2018 & $\begin{array}{l}\text { Liver } \\
\text { International: } \\
\text { oficial Journal of } \\
\text { the International } \\
\text { Association for } \\
\text { the study of the } \\
\text { Liver. }\end{array}$ & $\begin{array}{l}\text { Descrever as características clínicas e virológicas } \\
\text { dos pacientes com HDV e o tratamento em } \\
\text { diferentes regiões ao redor do mundo. }\end{array}$ & $\begin{array}{l}\text { O estudo destaca a heterogeneidade das } \\
\text { características dos pacientes e dos desfechos } \\
\text { clínicos em diferentes regiões do mundo. Há uma } \\
\text { necessidade urgente de opções terapêuticas para } \\
\text { o tratamento da infecção por HDV. }\end{array}$ \\
\hline Zhang Z (2018) & 2018 & $\begin{array}{l}\text { Journal of } \\
\text { Hepatology }\end{array}$ & $\begin{array}{l}\text { Caracterizar a ativação do IFN pelo HDV e avaliar } \\
\text { o efeito do IFN na replicação do HDV. }\end{array}$ & $\begin{array}{l}\text { A replicação ativa do HDV induz uma resposta } \\
\text { pelo IFN alfa e beta, a qual é predominantemente } \\
\text { mediada pelo MDA5. Essa resposta do IFN e o } \\
\text { tratamento IFN exógeno gera um efeito moderado } \\
\text { na replicação do HDV in vitro, indicando a } \\
\text { adaptação do vírus. }\end{array}$ \\
\hline $\begin{array}{l}\text { Chabrolles H, et } \\
\text { al., (2018) }\end{array}$ & 2018 & $\begin{array}{l}\text { Medecine } \\
\text { sciences: M/S }\end{array}$ & $\begin{array}{l}\text { Tratar sobre as múltiplas funções da proteína core } \\
\text { do vírus da hepatite B }\end{array}$ & $\begin{array}{l}\text { A terapia atual reduz a viremia, mas não retira o } \\
\text { vírus dos hepatócitos, por isso há necessidade } \\
\text { urgente de desenvolver novos fármacos. }\end{array}$ \\
\hline
\end{tabular}

Fonte: Costa PLS, et al., 2019. 
A partir dos artigos evidenciou-se que ambos os vírus são transmitidos, principalmente, por via sexual. Mas também podem ser por via vertical, transfusional e parenteral (SILVA ALS, et al., 2013; RIZZETO M, 2015; COGHILL S, et al., 2018). Diferentes autores mencionaram que fatores socioculturais como, densidade populacional, realização de tatuagens, atividade sexual são importantes na transmissão. Além de que fatores de constituição genética da população amazônica são prováveis mediadores da resposta imunológica favorecendo a manutenção do estado de portador do VHB nessa região (BOTELHO SOUZA LF, et al., 2017; RIZZETO M., 2015; WRANKE A., et al., 2017).

Quanto à variabilidade genética, afirmou-se que o HBV possui alta variabilidade, a qual compreende oito genótipos bem característicos, $\mathrm{A}$ ao $\mathrm{H}$, além de mais dois novos genótipos propostos, I e J, com apresentação distinta de acordo com a distribuição geográfica variável, além de influenciar nas manifestações clínicas. A Amazônia brasileira (delimitando as áreas: bacias dos rios Juruá, Solimões e Purus, no estado do Amazonas) é considerada uma região com alta endemicidade para o HBV e HDV, em que o quais representam importantes problemas de saúde pública com casos graves de hepatite aguda e crônica por HDV (CRISPIM MAE, et al., 2014). O genótipo A do HBV prevalece no Brasil, seguido dos genótipos D e F, o mais recente. Sendo que o genótipo $\mathrm{F}$ é mais encontrado em tribos indígenas isoladas da sociedade. Quanto ao HDV, predomina no Brasil o genótipo 3. A diferença de genótipo pode implicar no resultado do tratamento. Estudos revelam que pacientes portadores de HBV com os genótipos A e B possuem uma melhor resposta a terapia baseada no interferon quando comparados aos portadores do genótipo C e D (CRISPIM MAE, et al., 2014).

A apresentação clínica pode variar conforme a forma em que a infecção ocorreu e é descrita de maneira bem variada na literatura. A maioria dos autores dividem em superinfecção, que corresponde à doença em que o paciente já possuía o vírus da Hepatite $B$ e posteriormente adquiriu o HDV; e coinfecção, que corresponde ao paciente que adquiriu os dois vírus ao mesmo tempo (MINISTÉRIO DA SAÚDE, 2015). A coinfecção, cursa como uma hepatite aguda, a qual pode ser monofásica ou bifásica, sendo a primeira fase dependente do HBV e a segunda apenas do HDV. Enquanto a superinfecção desenvolve uma hepatite fulminante com maior risco de cirrose carcinoma hepatocelular. Os pacientes que possuíam hepatite B assintomática passam a desenvolvê-los nesse momento e os pacientes sintomáticos possuem somente exacerbação dos sintomas (BOTELHO-SOUZA LF, et al., 2017).

O curso da hepatite $D$ é extremamente dependente do HBV. No caso da coinfecção, o paciente cursa com uma hepatite $B$ e $D$ agudas com tempo de incubação dependente do título do inóculo inicial e progressão autolimitada. Os sintomas surgem em 3 a 7 dias e, dentre eles, destaca-se: fadiga, anorexia, náuseas e icterícia. Apenas $5 \%$ dos pacientes evoluem à forma crônica. Enquanto a superinfecção ocasiona uma hepatite aguda grave com incubação curta e cronificação em $80 \%$ dos casos. O indivíduo pode desenvolver uma hepatite fulminante ou crônica severa, evoluindo com mal prognóstico. A evolução para a cirrose ocorre cerca de 2 anos após a infecção. A mortalidade é cerca de dez vezes maior nessa superinfecção que na hepatite $B$ isolada (MINISTÉRIO DA SAÚDE, 2015).

Desse modo, o momento em que a doença é adquirida e a correlação com infecção prévia ou não pelo HBV influencia diretamente na história natural da doença, curso clínico e possíveis complicações, conforme ressaltado no Quadro 3.

Quadro 3 - Dados que diferenciam a superinfecção e a coinfecção.

\begin{tabular}{|l|l|}
\hline \multicolumn{1}{|c|}{ SUPERINFECÇÃO } & \multicolumn{1}{c|}{ COINFECÇÃO } \\
\hline O paciente já era portador do HBV quando & O paciente contrai os 2 vírus ao mesmo tempo; \\
contraiu o HDV; & Hepatite aguda monofásica ou bifásica; \\
Hepatite aguda fulminante; & Tempo de incubação variável; \\
Tempo de incubação curto; & Pouca tendência à cronificação; \\
Grande tendência à cronificação; & \\
\hline
\end{tabular}

Fonte: Costa PLS, et al., 2019. 
Não foi encontrado na literatura pesquisada discordância à cerca do diagnóstico da coinfecção HVB/HVD. Desta forma, o primeiro passo para o diagnóstico do HDV foi o desenvolvimento de sorologias específicas, como o anti-HDV $\operatorname{lgM}$ e $\mathrm{lgG}$, em pacientes com positividade para $\mathrm{HbsAg}$ e com elevação de aminotransferases, e carga viral do HBV $<2.000 \mathrm{UI}$ (unidades). Se o paciente apresentar algum destes positivos, é necessário a realização do HDV-RNA, para determinar se a presença do anticorpo reflete uma infecção ativa ou não e também qual o genótipo infectante. Se o mesmo der negativo, é recomendando que o exame seja repetido (SBH, 2015; SHIRVANI-DASTGERDI E., 2016). Se necessário, também pode ser realizada a biópsia hepática com histopatologia, esta é capaz de estabelecer um diagnóstico definitivo, associada a métodos bioquímicos inespecíficos como ALT/AST (Alanina aminotransferase/Aspartato aminotransferase). Além disso, esses pacientes devem ser pesquisados para outros vírus, como o vírus da hepatite C (BOTELHO-SOUZA LF, et al., 2017). É imprescindível distinguir qual o tipo de infecção (co-infecção ou superinfecção), já que o manejo para cada tratamento é diferente (SBH, 2015).

Para o Ministério da saúde, as recomendações de diagnóstico consistem na presença do HBsAg ou Anti$\mathrm{HBclgM}$ ou HBeAg reagentes associados a 1 ou mais marcadores sorológicos que confirmem a hepatite delta, são eles: Anti-HDV total reagente e/ou Anti-HDV IgM (imnunoglobulina M) reagente. Lembrando que é recomendado que todo paciente $\mathrm{HBs} A g$ positivo seja investigado para hepatite $\mathrm{D}$, se morar em área endêmica ou tiver viajado para tal (MINISTÉRIO DA SAÚDE, 2015; NOUREDDIN M, et al., 2014). Como forma de observar o comportamento infecioso são utilizados a mensuração de vírus presente no sangue (carga viral/HBV-DNA), uso de marcadores sérico de imunidade (anti-HBs), examinar do antígeno presente na superfície do HBV (HBsAg). Conforme a depleção do HbsAg e da carga viral, juntamente ao surgimento do anti-HBsAg, sugerem solução da infecção pelo HBV, em sua maioria. Pontualmente, há a possibilidade de evolução da doença para sua forma crônica, ainda que haja o perfil viral e sorológico (MINISTÉRIO DA SAÚDE, 2017).

Histopatologicamente, a hepatite aguda por HDV se apresenta com necrose e inflamação hepatocelular com injúria focal, porém não é um achado específico de hepatite $D$, entretanto, são achados de caráter mais intenso nessa doença. No caso da hepatite D crônica, os achados são iguais aos da aguda, acrescentandose somente o aparecimento de áreas fibrosadas. Por outro lado, o HDAg é encontrado em quantidade reduzida na forma crônica da doença e na forma aguda é encontrado em grande quantidade (BOTELHOSOUZA LF, et al., 2017).

A hepatite $B$ e $C$ frequentemente levam à cirrose, fibrose e carcinoma hepatocelular como complicações. 18 A coinfecção HBV/HDV aumenta ainda mais o risco para o desenvolvimento deste câncer, ainda que a replicação do HBV seja suprimida pelo HDV (SHIRVANI-DASTGERDI E., et al., 2016; MAKHLOUF NA, 2019). Além disso, a progressão da doença hepática torna-se muito mais rápida, devido ao maior estímulo ao sistema imune, que, na tentativa de eliminar o vírus, degrada progressivamente o tecido hepático (SHIRVANIDASTGERDI E, et al., 2016 e YURDAYDIN C, et al., 2019).

Infecções de longo tempo pelo HDV gera aumento do estresse oxidativo nos hepatócitos, inflamação imunomediada, mutações e câncer. Enquanto o HBV contribui para o desenvolvimento do câncer por meio da hipo e hipermetilação do DNA, aumentando os riscos de mutações. (SHIRVANI-DASTGERDI E., et al., 2016). Comparando com as outras hepatites virais, o HDV é o maior responsável por essa evolução desfavorável citada. Também são citados outros fatores que relacionados a essa coinfecção aumentam significativamente o risco de cirrose e $\mathrm{CHC}$ (Carcinoma hepatocelular), são eles: níveis muito elevados do HBV RNA, idade avançada, gênero masculino, níveis muito elevados de ALT, grande quantidade de HBsAg e HBV genótipo C (FARCI P, et al., 2012). No Brasil, o escore de MELD-PELD (Model For End-Stage Liver Disease - Pediatric End-Stage Liver Disease) e o Child-Pugh (Classificação de Child-Turcotte-Pugh) são recomendados para estabelecer o prognóstico do paciente e determina quais necessitam de transplante hepático (NOUREDDIN M., et al., 2014).

Quanto ao tratamento, suas indicações seguem recomendações em que haja a cirrose ausente ou presente, no indício de agressão hepatocelular (aumento de aminotransferases, fibrose, outros) e replicação viral relevante $(\mathrm{HBV}>2000 \mathrm{UI} / \mathrm{mL}$ - Unidades por $\mathrm{mL}$ ). Nesse sentido, o BEA score (baseline-event- 
antecipation) constitui um complemento muito útil nos pacientes infectados com hepatite $D$, pois ajuda na decisão de quais pacientes precisam ser tratados imediatamente (FARCI P e NIRO GA, 2012).

De acordo com o Ministérios da saúde brasileiro (MS), todos os pacientes portadores de hepatite Delta são candidatos à terapia composta por alfapeguinterferona 2a e/ou um análogo de nucleosídeo (tenofovir ou entecavir) (MINISTÉRIO DA SAÚDE, 2017). O interferon peguilhado constitui a melhor forma de terapia atual contra a coinfecção $B$ e delta, havendo boa eficácia em $40 \%$ dos pacientes, dos quais $25 \%$ passam a ter o RNA HDV negativo após 48 semanas (LORENC B, et al., 2017). Enquanto que análogos de nucleosídeos e nucleotídeos são considerados ineficazes contra o HDV, porém são úteis na infecção isolada do HBV, sendo sua terapia padrão (TAKLE, 2019). Após 1 ano de tratamento monoterápico espera-se HDV RNA negativo, caso contrário é indicado o acréscimo do segundo ano de tratamento (SILVA ALS, 2013). Além disso, destacase que o interferon é totalmente contraindicado em pacientes com cirrose descompensada. Para o controle de cura é analisada a negativação dos níveis de HDV RNA e normalização dos níveis de transaminases (BOTELHO-SOUZA LF, et al., 2017).

Seja qual for o tratamento, ele deve ser suspenso, caso haja: efeitos colaterais importantes; não aderência ao tratamento, situações em que há contraindicação do modelo de tratamento (ex.: gestação e alfapeguinterferona); reconhecimento de causa que necessita substituir o tratamento (ex.: insuficiência hepática). Entretanto, deve destacar que no meio científico a maioria dos autores consideram que o interferon atua melhor nas fases iniciais, quando o HDV ainda está entrando nos hepatócitos, sendo menos eficazes quando o mesmo já se encontra no meio intracelular (ZHANG, 2018; HAN Z., et al., 2011).

Por isso, novos medicamentos têm sido desenvolvidos, como o inibidor de entrada do HBV Myrcludex, inibidor de prenilação, interferon lambda e polímeros de ácido nucleico (TAKLE F, 2019; BOGOMOLOV P., et al., 2016; KOH C, et al., 2015). Destaca-se que as terapias atuais atingem principalmente a supressão viral, mas raramente a perda do antígeno, que é considerada uma cura funcional. Dentre as terapias atuais mais estudadas, destaca-se o Myrcludex B, o qual apresenta é muito bem tolerado e praticamente não apresenta efeitos colaterais, além de que seus efeitos supressores têm caráter progressivo, de modo que pode e deve ser usado em longa duração. Outro medicamento com bons resultados em ensaios clínicos é o lonafarnib, o qual apresenta vantagens em relação ao Myrcludex $\mathrm{B}$, pois seus efeitos apresentam resultados mais intensos de maneira mais precoce e possui resultados significativos até mesmo no tratamento da hepatite $D$ crônica (YURDAYDIN C, et al., 2019; BOGOMOLOV P, et al., 2016; KOH, et al., 2015) A doença pode ser reativada em situações de imunodepressão, exigindo uma terapia antiviral profilática (TAKLE F, 2019).

\section{CONSIDERAÇÕES FINAIS}

Em conclusão, vislumbra-se que é fundamental a realização de mais estudos acerca da coinfecção hepatite B e Delta, principalmente na região amazônica, devido sua grande prevalência. Os autores declaram terem encontrado limitações em relação a pouca quantidade de artigos atuais e cientificamente relevantes acerca do assunto. Por meio deste estudo, acredita-se que o meio científico será estimulado à produção de mais conhecimento acerca desta patologia, o que a longo prazo culminará no desenvolvimento de novas formas de prevenção e diagnóstico, assim como medicações mais eficazes e consolidação de novos fármacos que já estão em fase de teste. Além de proporcionar um prognóstico mais favorável aos pacientes, reduzindo o risco de desfechos negativos.

\section{REFERÊNCIAS}

1. BOGOMOLOV $P$, et al. Treatment of chronic hepatitis $D$ with the entry inhibitor myrcludex $B$ : first results of a phase Ib/lla study. J Hepatol 2016; 65:490-498.

2. BOTELHO-SOUZA LF, et al. Hepatitis Delta: virological and clinical aspects. Virology journal, 2017.

3. CHABROLLES $\mathrm{H}$, et al. The multiple fuctions of the hepatitis $\mathrm{B}$ virus core protein: new research directions and therapeutic challenges. Med Sci (Paris), 2018; 34 (8-9): 639-700. 
4. COGHILL S, et al. Epidemiology and clinical outcomes of hepatitis delta (D) virus infection in Queensland, Australia. International Journal of Infectious Diseases, 2018. 74, 123-127. doi: 10.1016/j.jij.2018.07.005

5. CRISPIM MAE, et al. Molecular epidemiology of hepatitis $B$ and hepatitis delta viruses circulating in the western amazon region, north Brazil. BMC infectious diseases, 2014, 14:94.

6. FARCI P, NIRO GA. Clinical features of hepatitis D. Semin Liver Dis 2012;32(3):228-36

7. GHADIR MR, et al. Prevalence of hepatitis $d$ virus infection among hepatitis $B$ virus-infected patients in qom province, center of iran. Hepat Mon 2012;12(3):205-8.

8. HAN Z, et al. Interferon impedes an early step of hepatitis delta virus infection. PLoS ONE 2011;6 e22415.

9. $\mathrm{KOH} \mathrm{C}$, et al. Oral prenylation inhibition with lonafarnib in chronic hepatitis $D$ infection: a proofof-concept randomised, double-blind, placebo-controlled phase 2A trial. Lancet Infect Dis 2015; 15:1167-1174.

10. LORENC B, et al. Hepatitis $\mathrm{D}, \mathrm{B}$ and $\mathrm{C}$ virus (HDV/HBV/HCV) coinfection as a diagnostic problem and therapeutic challenge. 2017

11. MAKHLOUF NA, et al. Hepatitis D virus infection among hepatitis B virus surface antigen positive individuals in Upper Egypt: Prevalence and clinical features. Journal of Infection and Public Health. doi: 10.1016/j.jiph.2018.12.001

12. MINISTÉRIO DA SAÚDE. Boletim epidem Hepatites Virais - Sistema de vigilância em Saúde - Brasil, 2018.

13. MINISTÉRIO DA SAÚDE. Manual técnico para diagnóstico das hepatites virais. Brasília, 2015

14. MINISTÉRIO DA SAÚDE. Protocolo clínico e diretrizes terapêuticas para hepatite B e coinfecções. Brasília, 2017.

15. NOUREDDIN M, GISH R. Hepatitis Delta: Epidemiology, Diagnosis and Management 36 years after discovery. Curr Gastroenterol Rep (2014) 16:365.

16. OLIVEIRA MS, et al. Hepatite B crônica e a superinfecção por vírus D em pacientes na Amazônia Ocidental brasileira. Rev Epidemiol Control Infect. 2015; 5(2):72-78.

17. RIZZETTO M. Hepatitis D virus: introduction and epidemiology. Cold Spring Harbor Perspect Med 2015;5 a021576.

18. SHIRVANI-DASTGERDI E, et al. Hepatocarcinogenesis associated with hepatitis $B$, delta and $C$ viruses. Curr Opin 2016; $20: 1-10$.

19. SIEDERDISSEN CHZ, CORNBERG M. Management of HBV and HBV/HDV-Associated liver cirrhosis. Visceral Medicine, 2016.

20. SILVA ALS, et al. Hepatites virais: B, C e D: atualização. Rev Bras Med. SP, 2013; 10(3):206-18

21. SOCIEDADE BRASILEIRA DE HEPATOLOGIA. Recomendações da SBH para Diagnóstico e Tratamento das Hepatites B e Delta. 2015.

22. TAKLE F. Current and future therapy of Hepatitis B and D. Dtsch Med Wochenschr. 2019 Apr;144(8):528-534

23. VILLA DI FILIPPO D, et al. Hepatitis $D$ virus and hepatitis $B$ virus infection in Amerindia communities of the Amazonas state, Colombia. Virol J. 2015; 12:172

24. WRANKE A, et al. Clinical and virological heterogeneity of hepatitis delta in different regions world-wide: The Hepatitis Delta International Network (HDIN). Liver International, 2017, 38(5), 842-850. doi:10.1111/liv.13604

25. YURDAYDIN C, et al. Treating cronic hepatitis delta: The need for surrogate markers of treatment efficacy. Journal of Hepatology 2019 vol. 70.

26. ZHANG Z, et al. Hepatitis D virus replication is sensed by MDA5 and induces IFN-b/k responses in hepatocytes. J Hepatol 2018; 69:25-35. 